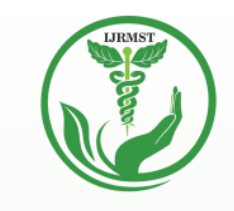

INTERNATIONAL JOURNAL OF RESEARCH IN MEDICAL SCIENCES \& TECHNOLOGY

e-ISSN:2455-5134; p-ISSN: 2455-9059

\title{
EMPLOYABILITY OF ADVANCED IMAGE PROCESSING TO EFFECTIVELY COUNT AND CLASSIFY THE BACTERIAL COLONIES
}

\author{
Bhavay Bajaj \\ Gateway International School
}

Paper Received: 04 ${ }^{\text {th }}$ September, 2021 ; Paper Accepted: 10 ${ }^{\text {th }}$ October, 2021;

Paper Published: $22^{\text {nd }}$ November, 2021

DOI: http://doi.org/10.37648/ijrmst.vl li02.013
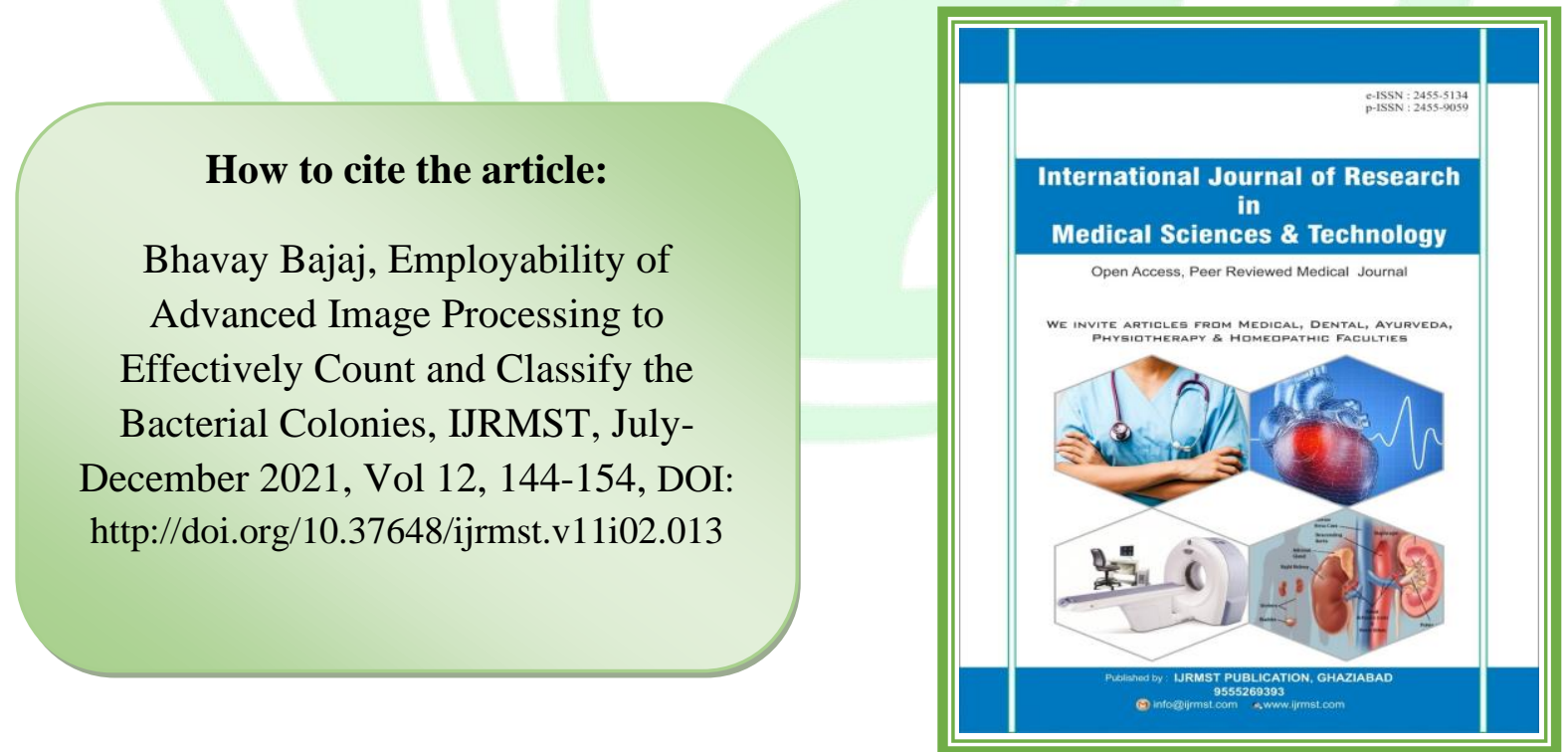


\section{ABSTRACT}

Specification of Bacterial Colonies is needed in many fields, such as clinical analysis, biomedical examination for anticipation of severe illnesses, and the drug industry to avoid tainting items. Existing Bacterial Colony counter frameworks count Bacterial Colony physically, which is a tedious, less effective and dreary cycle. Henceforth, mechanization for calculating bacterial settlement was required. The proposed strategy counts these settlements naturally utilizing picture handling strategies. This strategy will give a more superior level of precision in the counting of bacterial provinces. The proposed method takes a picture of bacterial settlement and converts it into grayscale. Otsu thresholding is applied for the division of the image, further its change into a double shot. From that point onward, morphological activities are used to tidy up the picture by eliminating commotion and superfluous pixels. Distance and watershed changes are applied to double vision to make parts among covered and joint microscopic organisms. Locale properties and marking data of fragmented picture is utilized for counting of the bacterial province.

\section{INTRODUCTION}

A bacterial Colony is characterized as a bunch of microscopic organisms got from one normal bacterium. Microbiologists require an exact proportion of the bacterial settlements for some natural systems [1]. Identification of Bacterial Colonies is significant for getting an accurate evaluation of microbes. Manual counting of bacterial colonies is a monotonous and tedious interaction. Mechanization of the method involved with counting bacterial provinces will save time and work needed for calculating settlements [2]. Picture division methods are utilized to mechanize this counting system. Picture division changes the picture into a structure appropriate for picture examination. In picture division, a computerized picture is partitioned into various sections. Picture division appoints marks to every pixel of a picture based on visual attributes. Picture division is utilized in numerous spaces, such as object discovery, picture recovery, object-based counting, tissue ID, cell counting, and item following [3]. Watershed division is broadly utilized for counting microorganisms. It is named the locale-based division approach. It is used to isolate two contacting items or covering objects. It considers the picture as a geological surface in which the dark level of every pixel is viewed as the tallness on a superficial level and the two covering or contacting objects as catchment bowls. 


\section{VOLUME: 12, JULY-DECEMBER 2021}

The rationale is to discover watershed edge lines isolating the two-catchment bowls for separating the two surrounding things [4] $[5]$.

\section{APPROACH}

The current work assembles a framework to count bacterial settlement, consequently utilizing picture preparing procedures. In the recent examination work, an experimental examination technique is used. A test system is planned and executed in MATLAB, showing the execution results. The framework is assembled and carried out in MATLAB $\mathrm{R} 2016 \mathrm{a}$, and the ,"m $\mathrm{m}^{\text {ee }}$ script is utilized to run the program. MATLAB has different apparatuses used in numerical, logical, designing and so forth. The picture handling apparatus of MATLAB is used for the proposed framework. Picture of bacterial settlement is utilized as information in the proposed framework in RGB design. These RGB pictures are changed over into grayscale images for training, and afterwards, further handling is done to accomplish the ideal outcomes.

\section{PLAN OF BACTERIAL COLONY COUNTER}

In the proposed method picture of the bacterial state is utilized for counting bacterial provinces. The image is changed over into a grayscale picture, and Otsu thresholding is applied to get the divided paired picture. The portioned paired picture isolates the closer view from the foundation.

Portioned paired pictures may contain some clamour and little components of no interest. Morphological activities are applied on this sectioned double picture to eliminate little details and clamour from it. Opening morphological activity is performed on the divided parallel image utilizing the square organizing component. The organizing component gets squeezed into the closer view areas in the picture and eliminates the forefront pixels where it can't fit. It eliminates little undesirable white pixels from the image and tidies up the concept for legitimate division. The picture is then supplemented coming about the closer view pixels as dark and foundation pixels as white.

Distance change is applied to this supplemented twofold picture creating a distance network to figure the distance of each pixel from nonzero-esteemed pixels. Watershed change is applied after the distance change that makes a named lattice yield. The named grid contains zero qualities for watershed edge lines that isolates the two covering microorganisms and nonzero-values for catchment bowls (covering microbes). Distance and watershed changes are called a watershed 


\section{VOLUME: 12, JULY-DECEMBER 2021}

division that partitions the covering and common microorganisms into portions. The district properties are extricated utilizing mass investigation from the picture, and the inclusion of bacterial settlements in the picture is shown.

\section{PROPOSED ALGORITHM OF PROPOSED SYTEM}

The proposed calculation for the proposed framework is as per the following:

1. The picture is perused in factor im.

2. Picture is changed over into grayscale and put away in a grey variable.

3. Thresholding is applied on the grayscale picture put away in grey variable utilizing MATLAB graythresh() capacity, and the resultant twofold image is put away in sifting variable.

4. Opening activity is applied on the sectioned parallel picture in sifting variable utilizing square organizing component and put away in factor open.

5. The opened picture in the open is supplemented so that forefront is dark in shading and the foundation is white in shading.

6. Distance change is registered in the supplemented picture that discovers the distance of each pixel from the closest non-zero-pixel esteems.
7. Watershed change is processed, taking distance change as a boundary that returns zeros for the watershed edge line and nonzero qualities for the catchment bowls. It gives yield as a marked framework.

8. The marked grid get in sync 7 is given tone in RGB space to recognize the fragments.

9. District properties are removed from the marked grid, and the number of microbes in the picture is shown.

\section{EXPLORATORY RESULT}

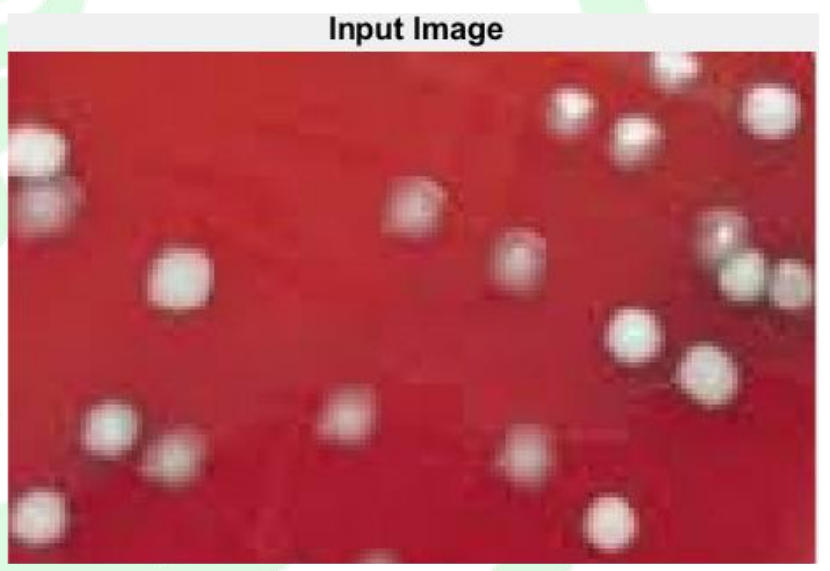

Fig 1: Bacterial Colony

\section{A. Contribution to the proposed}

\section{framework}

The picture of bacterial settlement in the RGB design displayed in preview 1 is utilized for counting bacterial states. The image has been downloaded from the web, and it is changed over into proper structure before applying procedure on it for the counting system of provinces. This 
proposed strategy picture is first changed over into a grayscale image and afterwards into a similar picture before doing additionally handling.

\section{B. Output of the proposed framework}

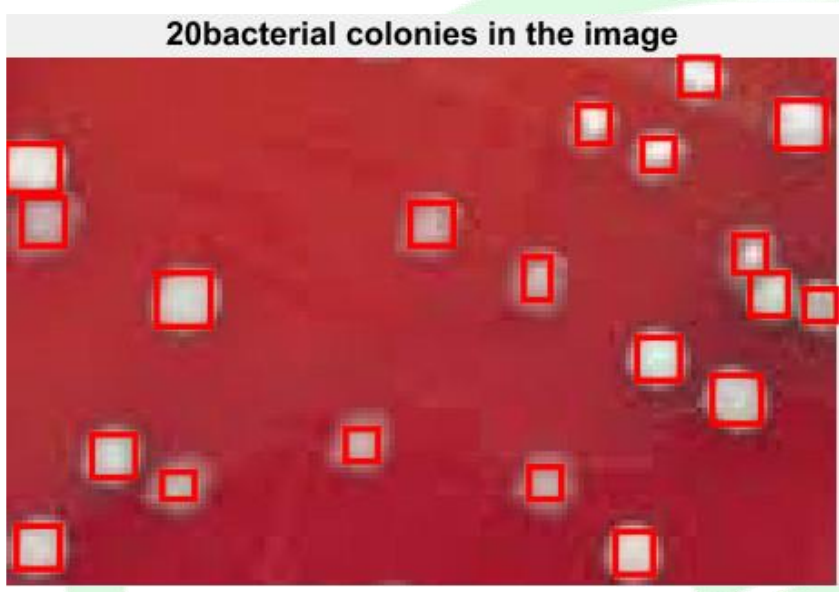

In depiction 2, the count of bacterial settlements is displayed as yield for the contribution to preview 1 . The result is acquired by applying watershed division that isolates the covering bacterial adjustments. Area properties of the picture are disengaged from the portioned image to count the isolated bacterial states.

Fig 2: Count of Bacterial Colony 
VOLUME: 12, JULY-DECEMBER 2021

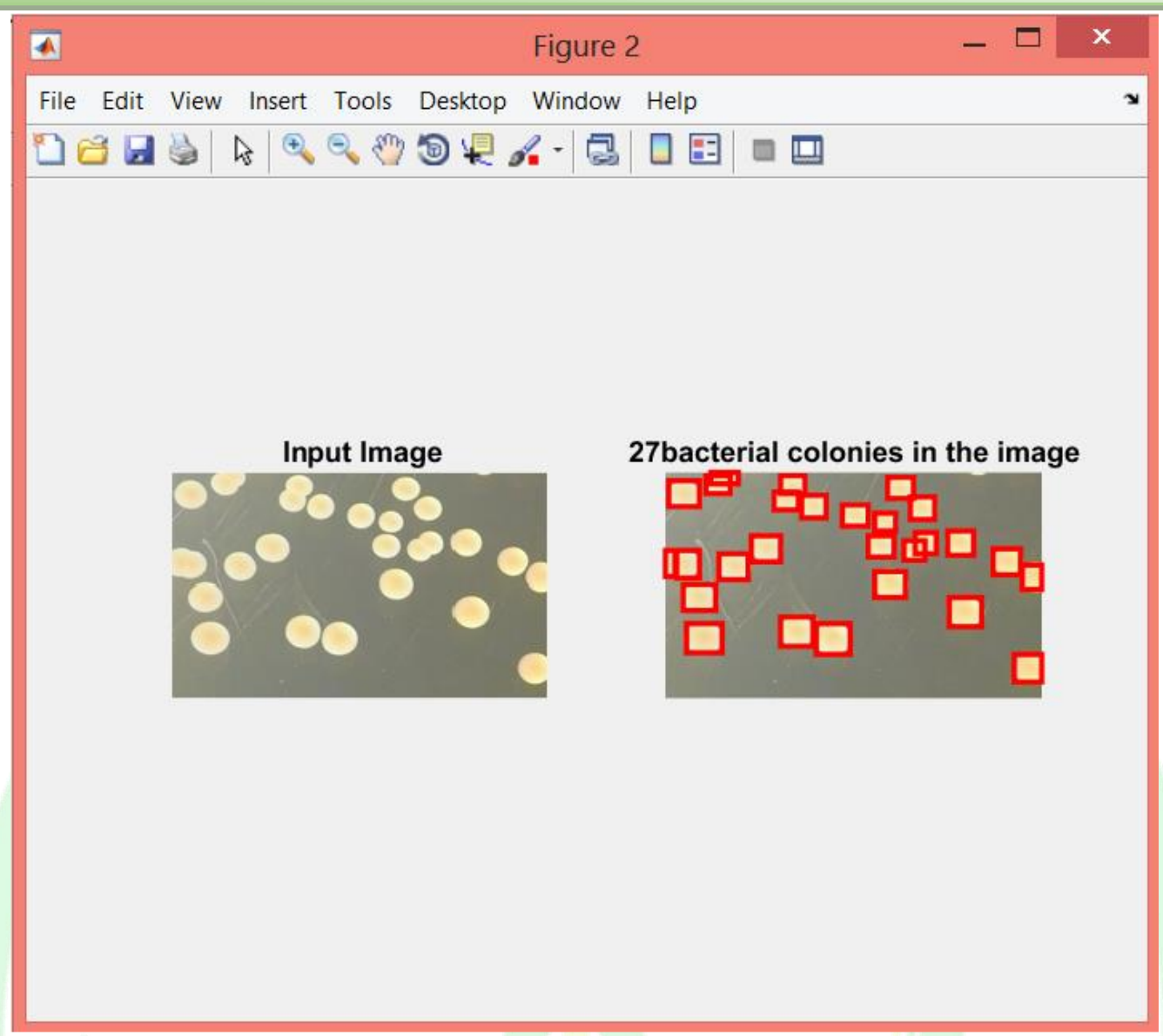

Fig 3: comparison of Images

Depiction 3 contains two windows. A picture of bacterial settlement is shown in one window, and in another window, the yield showing the count of the bacterial state is shown. The product is obtained by executing the proposed framework, and red tone jumping confines the net to recognize the bacterial provinces. 


\section{VOLUME: 12, JULY-DECEMBER 2021}

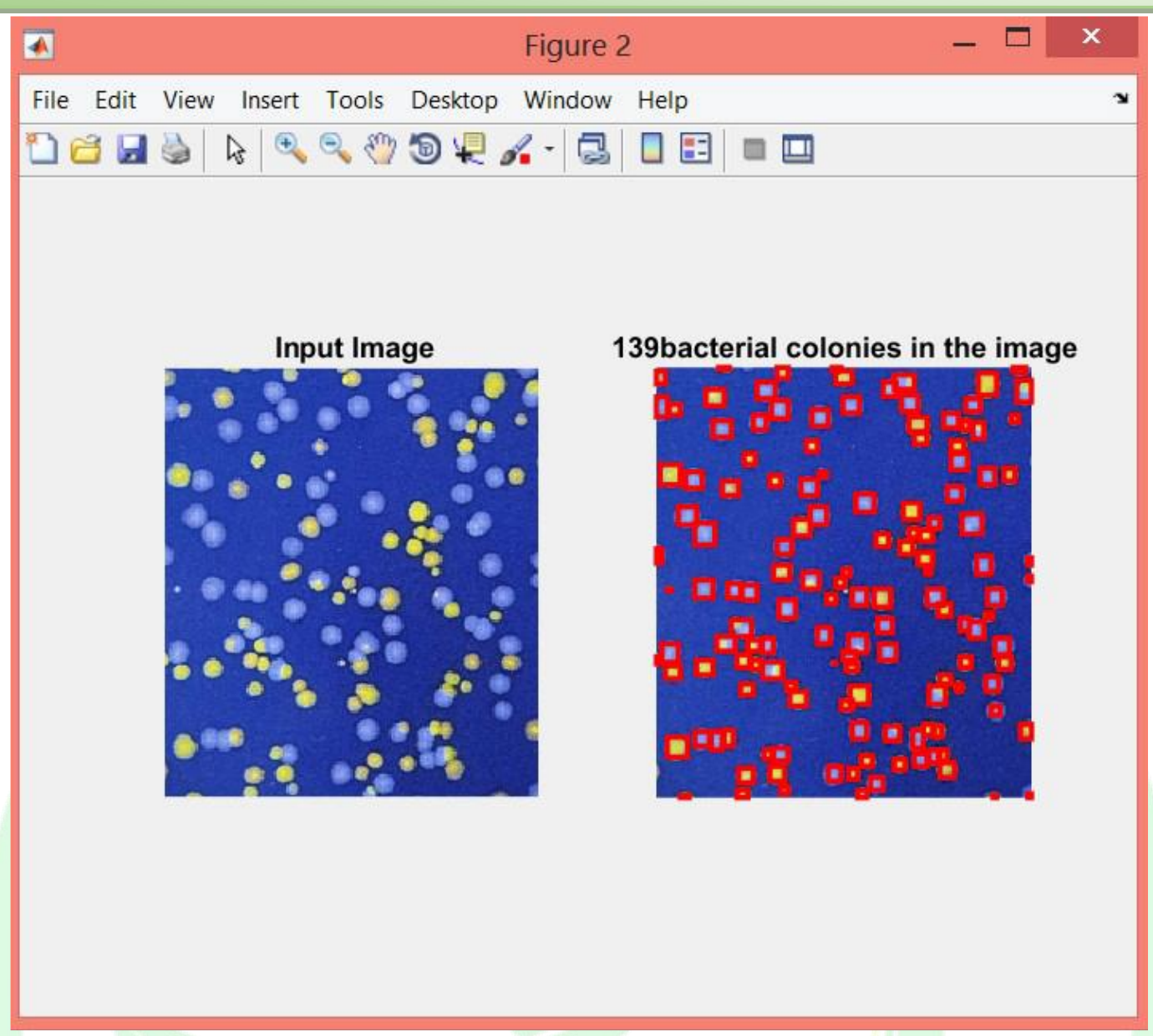

In preview 4, one more picture of the bacterial province and its yield showing the count of the bacterial state is shown. The expanded number of bacterial settlements in the picture is inputted into the test system, and the test system gives precise consider of bacterial provinces yield. 
VOLUME: 12, JULY-DECEMBER 2021

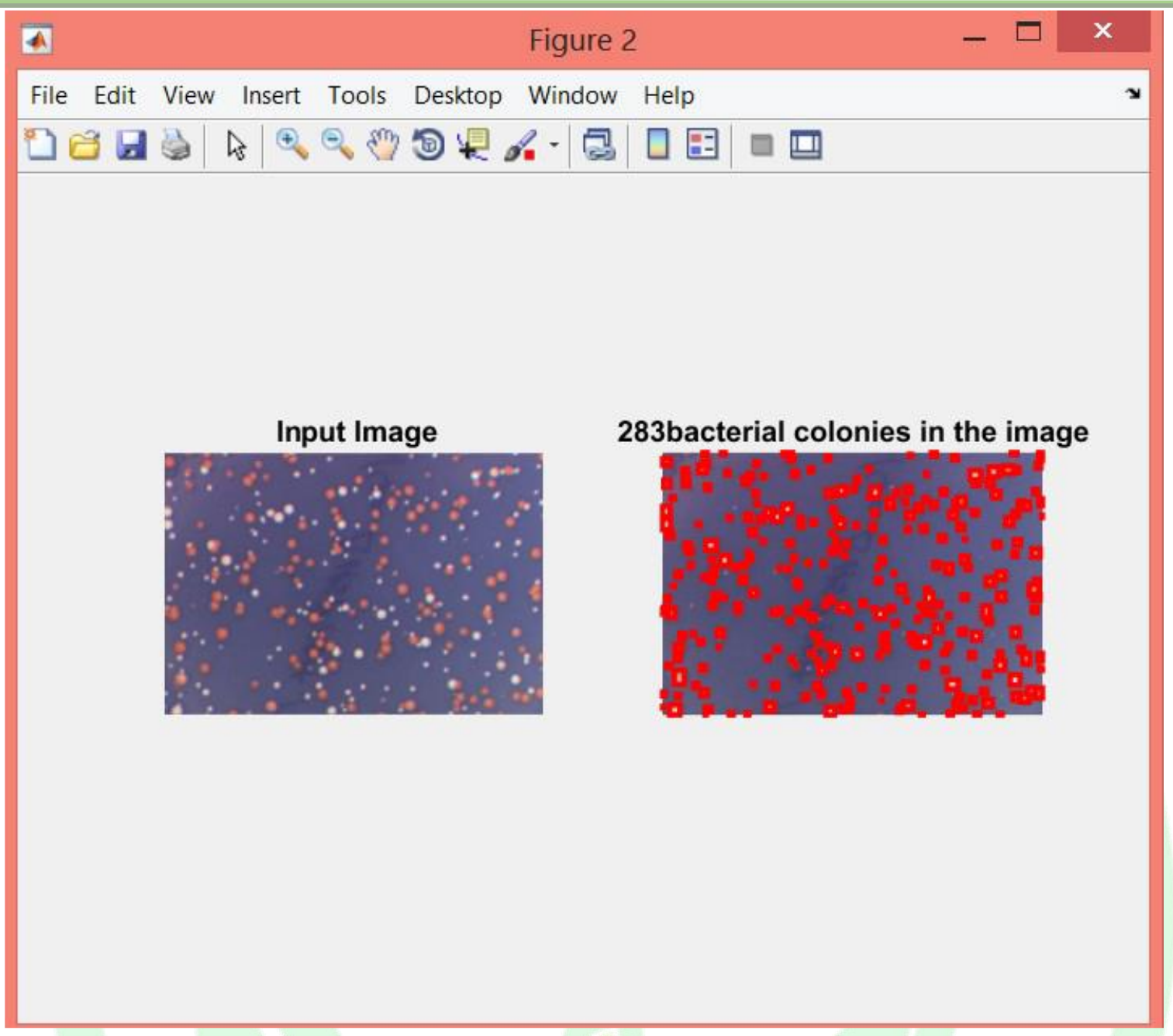

In preview 5, the quantity of bacterial provinces in the picture is expanded double the past image in depiction 4 . This picture contributes to the test system, and the proposed framework is then executed on the photo to get the exact count.

Aftereffects of the test system are summed up in table 1 as under:

\begin{tabular}{|c|c|c|}
\hline Sr.No & Proposed Count & Manual Count \\
\hline 1 & 20 & 20 \\
\hline 2 & 27 & 27 \\
\hline 3 & 139 & 139 \\
\hline 4 & 283 & 283 \\
\hline
\end{tabular}




\section{VOLUME: 1 2, JULY-DECEMBER 2021}

Above table 1 shows the consequence of the count of bacterial settlements by utilizing various pictures for the proposed strategy. The table shows the count acquired by the proposed method and the manual technique.

\section{CONCLUSION}

We infer from the outcomes that the "picture handling based bacterial state counter" is superior to the conventional technique for manual counting of bacterial provinces. It is unmistakably clear from Table 1 that the proposed framework produces exact outcomes. The distinction between the manual count and the robotized count is zero. Four products are displayed in the table in Table 1. The bacterial state with 20, 27, 139, 283 microorganisms are counted utilizing mechanized cycle, and the aftereffect of computerized measure is same as manual count technique, accordingly delivering exact outcomes. Manual counting of states is a dreary and tedious assignment, and the proposed framework has facilitated this undertaking. The odds of mistakes are likewise decreased. Few morphological tasks are utilized in the proposed framework since they must change morphological activity boundaries physically as per the picture, so full usage is unwanted. The proposed framework can even work for high thickness bacterial states pictures productively.

\section{REFERENCES}

[1] Hemlata Sethi and Sunita Yadav, "Bacterial Colony Counter: Manual vs Automatic", IRACST-Engineering Science and Technology: An International Journal (ESTIJ), 2012.

[2] Navneet Kaur Uppal and Raman Goyal, "Computational Approach to Count Bacterial Colonies", International Journal of Advances in Engineering \& Technology, Sept 2012.

[3] S.T Khandre, Akshay D. Isalkar, "A Survey Paper on Image Segmentation”, International Journal of Computer Science and Mobile Computing (IJCSMC), Vol 3 Issue.1, January 2014, Pg 441-446.

[4] Jos B.T.M. Roerdink and Arnold Meijster, "The Watershed Transform: Definitions, Algorithms and Parallelization Strategies", Institute for Mathematics and Computing Science University of Groningen, IOS Press 2009. 


\section{VOLUME: 12, JULY-DECEMBER 2021}

[5] Lamia Jaafar Belaid and Walid Mourou, "Image Segmentation: A Watershed Transformation Algorithm”, 2009.

[6] Hasamukh Patel and Dr. Priya Swaminarayan, "Automated Counting of Bacterial Colonies: Simple Contrast Stretching Algorithm", International Journal of Advanced Research in Computer Science and Software Engineering, Volume 5, Issue 9, September 2015 .

[7] Jacey-Lynn Minoi, Tin Tze Chiang, Terrin Lim, Zaharin Yusoff Abdul Hafiz Abdul Karim, Azham Zulharnain, "Mobile Vision-based Automatic Counting of Bacteria Colonies", IEEE, 2016.

[8] Rafael C. Gonzalez and Richard E. Woods, "Digital Image Processing in MATLAB Third Edition", USA, Pearson Prentice Hall, 2008.

[9] Salem Saleh Al-amri, N.V. Kalyankar and Khamitkar S.D, "Image Segmentation by Using Threshold Techniques”, JOURNAL OF COMPUTING, MAY 2010.

[10] Ms. K. Priyadharshini and Ms. Tripty Singh, "Research and Analysis on Segmentation and Thresholding Techniques", International Journal of Engineering Research \& Technology (IJERT), December 2012.

[11] P.P. Acharjya, A. Sinha, S. Sarkar, S. Dey and S. Ghosh, "A New Approach of Watershed Algorithm Using Distance Transform Applied to Image Segmentation”, International Journal of Innovative

Research in Computer and Communication Engineering, April 2013.

[12] Nick Efford, "Digital Image Processing: A Practical Introduction Using JavaTM." Pearson Education, 2000.

[13] Nilima Shah, Dhanesh Patel and Anjali Jivani, "Review on Image Segmentation, Clustering and Boundary Encoding”, International Journal of Innovative Research in Science, Engineering and Technology, November 2013. [14] L. Najman and M. Schmitt, "Watershed of a continuous function", In Signal Processing (Special issue on Mathematical Morphology.), 1994.

[15] Waseem Khan, "Image Segmentation Techniques: A Survey", Journal of Image and Graphics December 2013. 


\section{VOLUME: 12, JULY-DECEMBER 2021}

[16] Arindrajit Seal, Arunava Das and Prasad Sen "Watershed: An Image Segmentation Approach", International Journal of Computer Science and Information Technologies, 2015.

[17] K. Bhargavi and S. Jyothi, "A Survey on Threshold Based Segmentation Technique in Image Processing", International Journal of Innovative Research \& Development, November 2014.

[18] Li Haitao and Li Shengpu, "An Algorithm and Implementation for Image Segmentation", International Journal of Signal Processing, Image Processing and Pattern Recognition 2016. 